\title{
Transport of Neuronal BC1 RNA in Mauthner Axons
}

\author{
Ilham A. Muslimov, ${ }^{1}$ Margaret Titmus, ${ }^{3}$ Edward Koenig, ${ }^{3}$ and Henri Tiedge ${ }^{1,2}$ \\ Departments of ${ }^{1}$ Physiology and Pharmacology and ${ }^{2}$ Neurology, State University of New York, Health Science Center at \\ Brooklyn, Brooklyn, New York 11203, and ${ }^{3}$ Department of Physiology and Biophysics, State University of New York at \\ Buffalo, Buffalo, New York 14214
}

In neurons, localized RNAs have been identified in dendrites and axons; however, RNA transport in axons remains poorly understood. Here we analyzed axonal RNA transport in goldfish Mauthner neurons in vivo. BC1 RNA, a noncoding RNA polymerase III transcript that is targeted to dendrites in neurons of the rodent nervous system, was used as a probe for axonal RNA transport. Somata of Mauthner neurons were microinjected with various RNAs. Full-length BC1 RNA, but not control RNAs of similar length, was targeted to both axons and dendrites of Mauthner neurons. BC1 RNA was transported in the form of a rapidly advancing wave front that progressed along axons, in a microtubule-dependent manner, at a rate of 2 $\mu \mathrm{m} / \mathrm{sec}$. Whereas a $\mathrm{BC} 15^{\prime}$ segment of 65 nucleotides was transported to axons and dendrites in a way indistinguishable from full-length BC1 RNA, a BC1 3' segment of 60 nucleotides did not enter Mauthner cell processes to any significant extent. In the wake of the wave advancing through the axon, BC1 RNA was found localized to discrete, spatially delimited domains at the axonal surface. Such demarcated cortical concentrations of BC1 RNA could not be observed after disruption of F-actin organization in the axon. It is concluded that the specific delivery of BC1 RNA to spatially defined axonal target sites is a two-step process that requires the sequential participation of microtubules for long-range axial transport and of actin filaments for local radial transfer and focal accumulation in cortical domains.

Key words: fast axonal transport; RNA localization; targeting element; axons; Mauthner neurons; microinjection
RNA transport and localization have been recognized as important mechanisms for plasticity and pattern formation in various eukaryotic cell types. In neurons, the targeted delivery of RNAs to sites of local translation in dendrites has been implicated in the long-term modulation of synaptic form and function (for review, see Kindler et al., 1997; Tiedge et al., 1999; Job and Eberwine, 2001). However, although RNA localization in dendrites has been well documented in recent years, evidence for RNAs in the axonal compartment has been a subject of controversial debate (for review, see Kindler et al., 1997; Koenig and Giuditta, 1999; Mohr, 1999; Tiedge et al., 1999; Alvarez et al., 2000; Eberwine, 2001; Job and Eberwine, 2001).

Use of diverse experimental systems to investigate axonal RNA localization may have contributed to some of this controversy. In invertebrates (e.g., squid) and lower vertebrates (e.g., fish), RNAs have been identified in various axonal preparations (for review, see van Minnen, 1994; Kindler et al., 1997; Koenig and Giuditta, 1999; Mohr, 1999; Job and Eberwine, 2001). Such RNAs typically include rRNA, tRNA, and mRNAs encoding cytoskeletal, motor, and soluble components (for review, see Koenig and Giuditta, 1999; Alvarez et al., 2000). Evidence indicating the presence of RNAs in mammalian axons has typically been limited to those systems that are accessible for analysis. For example, $\beta$-actin mRNA has been shown to be transported to, and localized at, axonal growth cones in developing mammalian neurons in culture

\footnotetext{
Received Jan. 14, 2002; revised March 4, 2002; accepted March 12, 2002.

This work was supported in part by a grant from the New York City Council Speaker's Fund For Biomedical Research (I.A.M.), by National Science Foundation Grants IBN 9604841 and IBN 0118368 (E.K.), and by National Institutes of Health Grant NS34158 (H.T.).

Correspondence should be addressed to Henri Tiedge, Department of Physiology and Pharmacology, State University of New York, Health Science Center at Brooklyn, 450 Clarkson Avenue, Brooklyn, NY 11203. E-mail: tiedge@hscbklyn.edu. Copyright (C) 2002 Society for Neuroscience 0270-6474/02/224293-09\$15.00/0
}

(Bassell et al., 1998; Zhang et al., 2001). In several cases, RNAs have also been identified in axons of mature mammalian neurons, including in particular mRNAs encoding neuropeptide precursors in axons of magnocellular hypothalamic neurons (for review, see Kindler et al., 1997; Mohr, 1999).

Whereas local protein synthesis has been documented in immature axons (Eng et al., 1999), in axonal growth cones (Campbell and Holt, 2001), and in regenerating axons (Zheng et al., 2001), no consensus appears to have been reached yet as to whether mRNAs are locally translatable in mature axons (for review, see Mohr, 1999; Tiedge et al., 1999; Job and Eberwine, 2001). However, ribosomes were identified in squid giant axons (Crispino et al., 1997; Martin et al., 1998; Bleher and Martin, 2001). Furthermore, identification of ribosomal domains in fish and mammalian axons (Koenig and Martin, 1996; Koenig et al., 2000), together with metabolic evidence of protein synthesis (Koenig, 1991; van Minnen, 1994; Koenig and Giuditta, 1999; Alvarez et al., 2000), supported the notion of protein-synthetic capacity in mature vertebrate axons.

Despite increasing evidence for the presence of RNAs in the axonal domain, however, little is known about targeted transport of RNAs along axons (Job and Eberwine, 2001). Transport rates have not been established for axonal RNAs, and cis-acting elements that specify such transport have not been identified; therefore, a functional dissection of axonal RNA transport was the goal of this work. For this purpose, we used neuronal BC1 RNA as a transport probe because this RNA has been detected previously in both dendrites and axons (for review, see Tiedge et al., 1999; Brosius and Tiedge, 2001). We report here that BC1 RNA is specifically transported along goldfish Mauthner cell axons. Axonal $\mathrm{BC} 1$ transport is rapid, depends on intact microtubules, and is mediated by a cis-acting targeting element in the $\mathrm{BC} 15^{\prime}$ 
domain. Moreover, local disruption of the actin cytoskeleton perturbs regional translocation and localization of BC1 RNA in the cortical zone.

\section{MATERIALS AND METHODS}

RNA preparation. RNA was in vitro transcribed in the presence of ${ }^{35}$ S-UTP. Full-length BC1 RNA [152 nucleotides (nt)] and a 5' segment of BC1 RNA (nt 1-65) were generated from plasmid pBCX607 as described previously (Muslimov et al., 1997). Please note that the length of the BC1 5' segment has been corrected from 62 to $65 \mathrm{nt}$. A $3^{\prime}$ segment of BC1 RNA (nt 93-152) was generated from plasmid pMK1 (Tiedge et al., 1991), nuclear U4 RNA (145 nt) from plasmid pSP6-U4 (Hausner et al., 1990), nuclear U6 RNA (107 nt) from plasmid pSP6-U6 (Hausner et al., 1990), and 64 and 144 nt irrelevant-sequence RNAs from the polylinker region of plasmid pSL300 (Brosius, 1989). RNAs were transcribed from linearized plasmids using SP6, T3, or T7 RNA polymerase, according to the manufacturer's protocols (Promega, Madison, WI). After transcription, excess unlabeled UTP was added to the reaction mixture to ensure that labeled transcripts were full-length. Transcripts were checked by PAGE to verify that no degradation had occurred during handling of the samples (Muslimov et al., 1997).

Microinjection of radiolabeled RNAs into Mauthner neurons in vivo. Goldfish (Carassius auratis), 7-12 cm in length, were used for all experiments. Animals were purchased from a commercial supplier and housed in aquaria maintained at $20-22^{\circ} \mathrm{C}$ on a fixed daily light/dark cycle. In preparation for an experiment, a fish was anesthetized with $0.3 \mathrm{gm} / 1$ tricaine methane sulfonate (MS-222), mounted in a chamber, and immobilized with an intramuscular injection of D-tubocurarine $(1-3 \mu \mathrm{g} / \mathrm{g}$ body weight) after the lower brainstem was exposed surgically. The fish was respired for the duration of the experiment with a continuous flow of aerated, dechlorinated tap water containing $0.15 \mathrm{gm} / 1 \mathrm{MS}-222$. Glass filament electrodes, pulled from $1.5 \mathrm{~mm}$ tubing, were used for microinjections. Electrode tips were broken, dipped into a solution of $20 \mu \mathrm{l}$ $\gamma$-methacryloxypolytriethoxy silane in $2 \mathrm{ml} 1$-chloronaphtaline, and dried overnight at $100^{\circ} \mathrm{C}$. The electrode tip was filled by suction with ${ }^{35} \mathrm{~S}$ labeled RNA, diluted 1:4-1:20 from the transcription reaction in diethyl pyrocarbonate-treated water. Mauthner cells were injected with RNAs in systematically varying concentrations to ensure that resulting labeling profiles were independent of injected amounts. Standard amounts (dilution 1:4) were injected for all time course experiments; low amounts (dilution 1:20) were injected to reveal focal accumulations of radioactive signal in axonal areas from which the wave front had passed (see Results). Electrodes were backfilled with $1.5 \mathrm{M} \mathrm{KCl}$ and Fast Green (20 $\mathrm{mg} / \mathrm{l})$ and had an electrical resistance of 2.5-8.0 $\mathrm{M} \Omega$ when measured in brain tissue.

Mauthner cell perikarya are located in the rostral medulla, and after decussating, the two large myelinated axons project the full-length of the spinal cord. In its rostral extent in goldfish, the Mauthner cell axon may vary from 40 to $80 \mu \mathrm{m}$ in diameter (Funch et al., 1981), after which it tapers in the lower spinal cord. For microinjection into a Mauthner cell perikaryon, the cell was electrophysiologically localized in the rostral cerebellar crests (i.e., a region between the facial lobe and cerebellum). Antidromic stimulation of the spinal cord at the midbody level produces a unique Mauthner cell signature of a large, short-latency, all-or-none negative field potential recorded in a region overlying the axon cap that ensheaths the initial axon segment. After the Mauthner cell perikaryon was impaled, a pulse of pressure (5-20 psi) was used to eject the RNA, which produced a transient decrease of the resting membrane potential that recovered subsequently. Mauthner myelinated axons lie in the floor of the fourth ventricle and can be microinjected under direct visual control after the vagal lobes are separated.

Local disruption of microtubules and F-actin in axoplasm. Microtubules and F-actin were disrupted by focal pressure microinjection of either 1 $\mu \mathrm{M}$ vinblastine or $10 \mu \mathrm{M}$ cytochalasin D into one of the two Mauthner axons, $\sim 4 \mathrm{~mm}$ distal to the cell body. The disrupting agent was filled at the tip and backfilled with $1.5 \mathrm{M} \mathrm{KCl}$ and Fast Green dye to monitor the effectiveness of the injection. Vinblastine, which is effective and specific in the submicromolar range, binds to free tubulin dimers (Wilson et al., 1974) and blocks tubulin dimer addition at the ends of microtubules by binding with high affinity to a low number of sites (Himes, 1991). It thereby prevents polymerization and effectively promotes microtubule disassembly. Cytochalasin D, similarly, binds with high affinity to the "fast growing" barbed ends of actin filaments in vitro (MacLean-Fletcher and Pollard, 1980). In vivo, it causes an energy-dependent collapse of the actin filament network into "filament foci" (Schliwa, 1982; Edmonds and Koenig, 1990). Radiolabeled BC1 RNA was microinjected into the somata of both Mauthner neurons before intra-axonal injection of either vinblastine or cytochalasin D (see Results for details). Axons and cell bodies with dendrites were isolated $1 \mathrm{hr}$ after BC1 injection and fixed as described below.

Isolation of Mauthner cell axoplasmic whole mounts. Because of the content and cytoskeletal organization of neurofilaments, native axoplasm behaves as an elastic solid and can be pulled out of its myelin ensheathment as a whole mount from very large fibers (Koenig, 1986). Mild denaturation transforms axoplasm into a plastic solid, which allows isolation from small myelinated fibers (Koenig et al., 2000). In the experiments described here, the brainstem was sectioned in situ at the rostral border of the cerebellum. It was isolated along with the spinal cord by dissection and placed in a modified Cortland physiological fish saline, composed of (in mM): $132 \mathrm{NaCl}, 5 \mathrm{KCl}, 3 \mathrm{NaH}_{2} \mathrm{PO}_{4}, 3.5 \mathrm{MgSO}_{4}$, 20 HEPES, 5.5 glucose, 2 EGTA, pH 7.4 (Koenig and Adams, 1982). The spinal cord was divided $\sim 2 \mathrm{~cm}$ posterior to the border of the cerebellum, and after meningeal investments were removed and cerebellum and vagal lobes were excised (Koenig, 1986), the remaining tissue was denatured by immersion in a solution of $50 \mathrm{~mm}$ zinc acetate (ZnOAc; Sigma, St. Louis, $\mathrm{MO}$ ) in $0.1 \mathrm{M}$ Tris aspartate, $\mathrm{pH} 5.0$, or in $50 \mathrm{~mm}$ tricine (Sigma), $\mathrm{pH} 4.9$, for $30 \mathrm{~min}$. The tissue was transferred to a slide in $10 \mathrm{~mm} \mathrm{ZnOAc}, 0.1 \mathrm{M}$ Tris aspartate, pH 5.5, and the axoplasm was pulled out of its ensheathment with a pair of micro-tweezers by grasping the protruding fiber stumps at the caudal surface of the cut spinal cord. Axoplasm shears at the initial segment and is attached to the slide surface with the aid of an eyebrow-hair tool after isolation.

Isolation of Mauthner cell bodies with dendrites. After axoplasmic whole mounts were isolated and attached to a slide, the tissue was transferred to $10 \mathrm{~mm} \mathrm{ZnOAc}$ and $0.1 \mathrm{M}$ Tris aspartate, $\mathrm{pH} 5.5$, in a dish, and a brainstem slice was prepared from which Mauthner cell bodies with dendrites were isolated by hand microdissection under a stereomicroscope (Koenig and Repasky, 1985). The slice included the rostral half of the cerebellar crests (i.e., brainstem segment that extended midway between the facial lobe and mid-cerebellar peduncles). Each dissected cell was picked up in a fluid-filled, small-loop tool fashioned from an eyebrow hair, and positioned on the slide near the attached axoplasmic whole mount from the same side.

Fixation of isolated specimens. After attachment of Mauthner cell components to the slide, the solution on the latter was drained, and the slide was immersed for $20 \mathrm{~min}$ in $3.75 \%$ formaldehyde (made from paraformaldehyde) buffered with $0.1 \mathrm{M}$ diethylmalonic acid (Aldrich, Milwaukee, WI), adjusted to $\mathrm{pH} 7.4$ with $\mathrm{KOH}$. The fixative on the slide was drained, the slide was washed in $0.1 \mathrm{M} \mathrm{NH}_{4} \mathrm{OAc}$ thrice, and either stored in $45 \mathrm{~mm} \mathrm{NH} 4 \mathrm{OAc}$ ( $\mathrm{pH} 4.5$ with acetic acid) in $70 \%$ ethanol or immediately drained and dried for autoradiography.

Autoradiography and data evaluation. Emulsion autoradiography was performed as described previously (Tiedge, 1991; Muslimov et al., 1997). Axons and somata/dendrites, mounted on microscope slides, were dipped in NTB2 nuclear track emulsion (Eastman Kodak, Rochester, NY), diluted $1: 1$ with HPLC water, allowed to dry at $18-22^{\circ} \mathrm{C}$ for $2 \mathrm{hr}$, and exposed at $4^{\circ} \mathrm{C}$ for 3-4 weeks. Samples were developed (Kodak D19, $50 \%$ strength; Kodak Rapid-Fix) and coverslipped with Kaiser's jelly (Banker and Goslin, 1998). Specimens were analyzed and photographed (Kodak Ektachrome 160T tungsten film) on a Nikon Microphot-FXA microscope using dark-field and phase-contrast optics. Digital photomicrographs were produced either directly, using a Sony 3CCD DKC-5000 camera, or by scanning photographic slides with a $35 \mathrm{~mm}$ film scanner (Nikon LS-3510AF). Adobe Photoshop and Adobe Illustrator were used to prepare digital images.

For time course experiments, standard amounts of full-length BC1 RNA or the BC1 5' segment were injected. Axonal labeling profiles were established by determining silver grain distribution patterns along axonal extents as follows. Because Mauthner somata were prepared separate from their cognate axoplasmic whole mounts, zero distance was defined as the proximal-most axonal point. The zero-distance point corresponded to the junction between the initial axon segment (which is ensheathed by a dense glial cap) and a greatly enlarged myelinated axon. $\mathrm{Zn}$-denaturation transforms the viscoelastic axoplasm into a plastic solid with considerable tensile strength that retains its in situ shape after isolation of the axoplasmic whole mount. The fluid-suspended whole mount was attached to the slide in a proximal-to-distal manner to ensure consistency of axonal zero-distance points and in situ lengths. To establish labeling profiles as shown in Figure 3, evaluation points were chosen 
at $1 \mathrm{~mm}$ intervals. To establish intensity maxima of wave fronts, evaluation points were set at consecutive $100 \mu \mathrm{m}$ intervals across the peak. At each evaluation point, silver grains were counted within a $100-\mu \mathrm{m}$-wide slab-like cross-section through the axoplasm.

RNA transport rates in Mauthner cell axons were established as follows. For each axon, the position of the intensity maximum of the advancing wave front was determined as described above. For any given time point, the average distance traveled by these peaks was calculated from the combined data obtained from all axons analyzed for that time point. These values were then converted into transport rates. Although the diameter of a Mauthner cell axon is somewhat variable along the axonal extent (see above), distances traveled by wave fronts at given time points were found to be independent of axonal diameter.

\section{RESULTS}

\section{Axonal and dendritic transport of BC1 RNA in Mauthner neurons}

Perikarya of goldfish Mauthner neurons were injected with fulllength radiolabeled BC1 RNA in vivo. Fishes were euthanized after specified periods of time that varied between 0.5 and $4 \mathrm{hr}$, depending on the type of experiment. Whole mounts of dissected Mauthner cells with dendrites and isolated axoplasm were then attached to slides and processed as described above. Because axons from the pair of Mauthner neurons decussate and cross the midline, left and right axons were aligned with the perikaryon of the contralateral axon. As is shown in Figure 1, soma-injected full-length BC1 RNA was delivered to both dendrites and axons of Mauthner cells. Significant labeling could be observed in the cell body, the dendrites, and along the axon of injected cells. Labeling extended to distal dendrites after a $2 \mathrm{hr}$ post-injection period. Axons were labeled at substantial distances from the cell body, indicating that axonal delivery of BC1 RNA was rapid (see below for details).

The BC1 labeling signal was nonuniformly distributed along the axon. Within the extent of the axon that was labeled, the distal-most area exhibited highest relative signal intensities in the form of a peak (attributable to an advancing wave front of transported RNA; see below). In this peak area, the labeling signal was high and appeared in patchy to uniform distribution (Fig. 1B). In more proximal regions, the labeling signal was still significant, but lower than in the peak area. When low concentrations of BC1 RNA (see Materials and Methods) were injected, radioactivity in this proximal-intermediate area (i.e., in the wake of the advancing wave front) was typically restricted to distinct superficial areas (Fig. 1C,D). Such focal concentrations of $\mathrm{BC} 1$ labeling indicate that radioactive BC1 RNA had accumulated in discrete, spatially circumscribed cortical domains of the axon.

Dendritic and axonal transport of BC1 RNA in Mauthner neurons was specific. This was demonstrated by injecting Mauthner neurons in vivo with RNAs of similar lengths but irrelevant sequences. A $144 \mathrm{nt}$ RNA of irrelevant polylinker sequence (pSL300) (Brosius, 1989) was not detectable in Mauthner cell axons after somatic injection (Fig. $1 F$ ). Cell bodies were strongly labeled, whereas dendrites were labeled only in the region directly adjacent to the soma (Fig. 1E). Analogous results were obtained with nuclear U4 RNA (Fig. 1G,H): the labeling pattern $2 \mathrm{hr}$ after injection was almost exclusively somatic, with very few autoradiographic silver grains detectable in proximal-most dendritic segments. In view of these results, delivery of BC1 RNA to axons or dendrites by way of unspecific, passive diffusion appears to have been unlikely.

Taken together, the results show that BC1 RNA is rapidly and selectively transported to axons and dendrites of goldfish Mauthner neurons. The data further indicate that BC1 RNA is specifi-
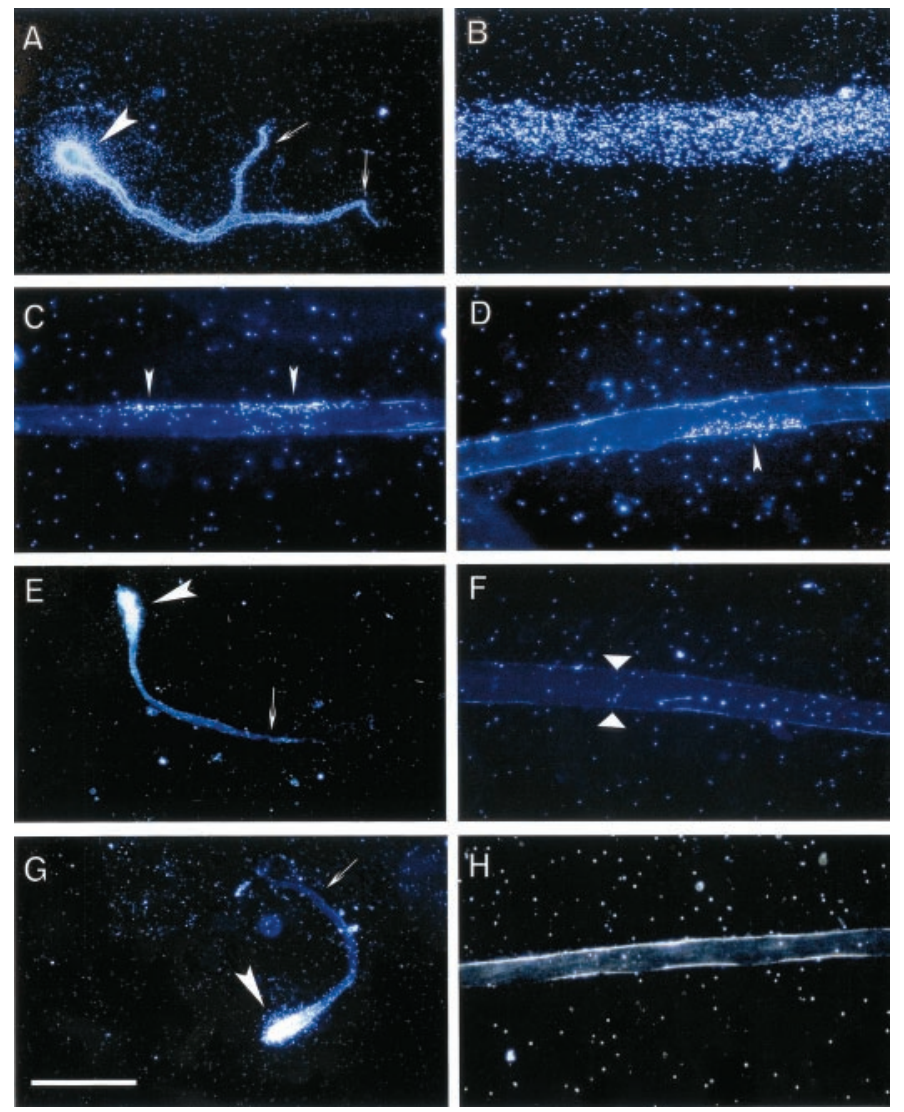

Figure 1. Transport and localization of microinjected BC1 RNA in Mauthner neurons. $A-D$, Full-length radiolabeled BC1 RNA was injected into the perikarya of Mauthner cells in vivo (total number of cells injected: 55). A, Two hours after injection, labeling signal was substantial over cell body (arrowhead) and dendrites, including distal dendritic regions (arrows). B, Significant labeling for BC1 RNA was apparent in the axoplasmic whole mount of the same cell. Photomicrograph was taken at a distance of $10 \mathrm{~mm}$ from soma. (The distance at this time point corresponds to the rear slope of the advancing wave, as shown in Fig. 3B.) The appearance of the labeling signal at this position was patchy to uniform. $C$, $D$, Focal accumulations of BC1 labeling signal (arrowheads) were revealed in the wake of the advancing front in axons. For these experiments, injection amounts were lowered below the typical amounts by a factor of 5 to ensure that labeling in the trailing part of the advancing wave would not obscure $\mathrm{BC} 1$ foci. $E-H$, Mauthner neurons were injected with an irrelevant-sequence RNA of $144 \mathrm{nt}(E, F$; number of cells injected: 4$)$ or with nuclear U4 RNA ( $G, H$; number of cells injected: 8). Post-injection intervals were $2 \mathrm{hr}$. Although injected somata were strongly labeled (E, $G$, arrowheads), no significant labeling was detected either in dendrites $(E, G$, arrows), except for a proximal-most region, or in axoplasmic whole mounts $(F, H$; distance from soma: $10 \mathrm{~mm})$. Arrowheads in $F$ indicate axonal boundaries. Please note that although Mauthner neurons typically have two dendrites, one may be lost during dissection. Scale bar (shown in $G): A, E, G, 100 \mu \mathrm{m} ; B-D, F, H, 50 \mu \mathrm{m}$.

cally recognized by the RNA transport machinery of Mauthner cells, and they prompt the question as to whether $\mathrm{BC} 1 \mathrm{RNA}$ contains a cis-acting element that would mediate such recognition.

\section{A cis-acting axonal and dendritic targeting element in the $\mathrm{BC} 15^{\prime}$ domain}

In rat sympathetic neurons, a $\mathrm{BC} 15^{\prime}$ segment of no more than 65 nucleotides has been shown previously to be competent to direct dendritic targeting, whereas $\mathrm{BC} 13^{\prime}$ sequences were found to be targeting-incompetent (Muslimov et al., 1997). Is the cis-acting element that is contained within the $\mathrm{BC} 15^{\prime}$ domain also respon- 

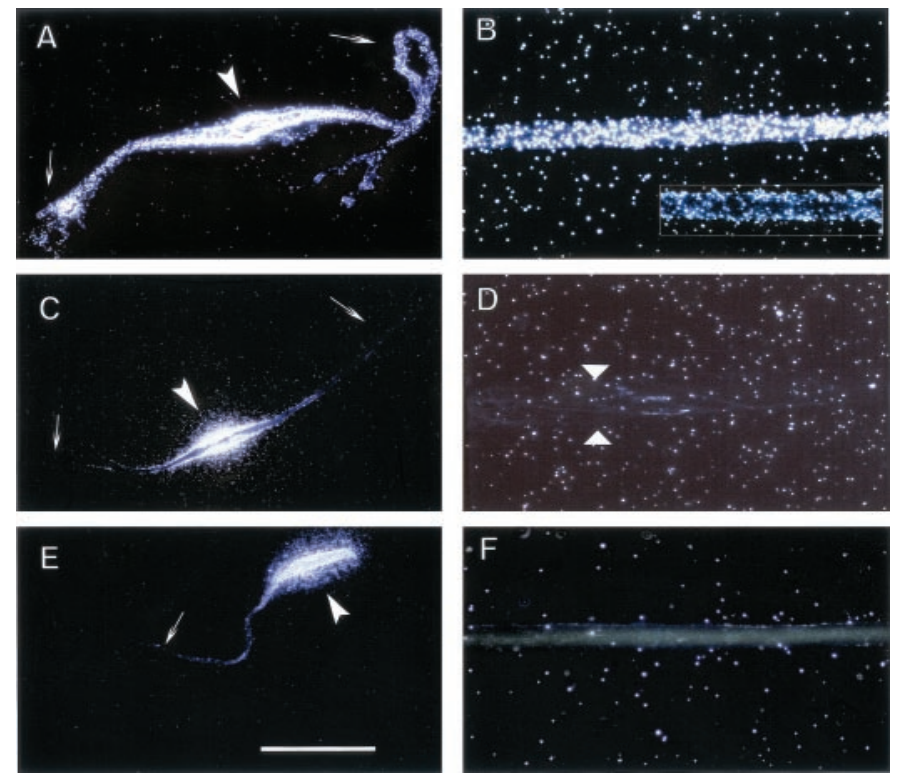

Figure 2. Transport competence of the BC1 5' domain in Mauthner neurons. Mauthner cell perikarya were injected in vivo with a BC1 5' segment ( $A, B$; number of cells injected: 46$)$, a BC1 $3^{\prime}$ segment $(C, D$; number of cells injected: 27$)$, or a 64 nt irrelevant-sequence RNA $(E, F$; number of cells injected: 5). Post-injection intervals were $2 \mathrm{hr} . A, C, E$, Somata/dendrites (arrows indicate dendrites; arrowheads indicate somata); $B, D, F$, axoplasmic whole mounts (photographed at $10 \mathrm{~mm}$ distance from somata). Microinjection of the $\mathrm{BC} 15^{\prime}$ segment resulted in labeling of somata and dendrites $(A)$ as well as along axoplasmic whole mounts $(B)$. Superficial accumulations of silver grains in cortical axonal domains were revealed after injection of low amounts of the BC1 $5^{\prime} \operatorname{segment}(B$, inset). After injection of a $\mathrm{BC} 13^{\prime}$ segment $(C, D)$, no significant labeling was observed along either dendrites $(C)$ or axons $(D$; arrowheads indicate axonal boundaries). Likewise, injection of a $64 \mathrm{nt}$ irrelevant-sequence RNA did not produce any significant dendritic $(E)$ or axonal labeling $(F)$. Scale bar (shown in $E$ ): $A, C, E, 100 \mu \mathrm{m} ; B, D, F, 50 \mu \mathrm{m}$.

sible for $\mathrm{BC} 1$ transport in Mauthner neurons? To address this question, 5' and BC1 3' segments, as well as appropriate control RNAs, were injected into Mauthner somata in vivo. As is shown in Figure 2, the $\mathrm{BC} 15^{\prime}$ segment (65 5'-most nt) was transported to both dendrites and axons, at significant levels and in a manner indistinguishable from full-length BC1 RNA. As with full-length $\mathrm{BC} 1$ RNA, the labeling signal for the $\mathrm{BC} 15^{\prime}$ segment appeared in the form of a wave front (see also below) (Fig. $3 A$ ). With low-level injections, cortical concentrations of silver grains were apparent in axonal areas posterior to the advancing wave, again similar to full-length BC1 RNA.

In contrast to full-length $\mathrm{BC} 1$ RNA or the $\mathrm{BC} 15^{\prime}$ segment, somatic injection of a $\mathrm{BC} 13^{\prime}$ segment (60 nt) did not result in any significant axonal labeling (Fig. 2D), although the soma was strongly labeled (Fig. 2C). Dendrites were not labeled, except for a low-level signal in dendritic segments immediately proximal to the soma. The central region of BC1 RNA, a stretch of 22 consecutive A-residues, was not analyzed for targeting competence. It should be noted that the subcellular labeling patterns after $\mathrm{BC} 1$ and control injections were independent of the amounts injected. For instance, injection of low amounts of the BC1 5' segment still resulted in significant axonal labeling (Fig. $2 B$ ). On the other hand, injection of standard amounts of a BC1 $3^{\prime}$ segment did not result in any noticeable "spillover" into dendritic (Fig. 2C) or axonal (Fig. 2D) compartments. Injected control RNAs, such as a 64 nt RNA of irrelevant sequence or nuclear
U6 RNA, did not produce any significant dendritic or axonal signal at standard-level injection routines that resulted in strongly labeled cell bodies (Fig. 2E,F) (and data not shown).

We conclude from these results that BC1 RNA contains, within a 5' segment of no more than $65 \mathrm{nt}$, a cis-acting targeting element that is sufficient to specify both axonal and dendritic BC1 transport in goldfish Mauthner neurons. The same 5' segment has been shown previously to contain a targeting element that is responsible for dendritic $\mathrm{BC} 1$ transport in rat sympathetic neurons (Muslimov et al., 1997). Our data therefore suggest that RNA transport machineries in both systems recognize similar or identical motifs within the $\mathrm{BC} 15^{\prime}$ domain.

\section{High velocity of axonal $\mathrm{BC} 1$ transport in Mauthner neurons}

To determine the velocity of BC1 transport in Mauthner cell axons, we adopted a modified classical pulse-labeling paradigm used to measure rapid axonal transport in the cat (Ochs, 1972). In these experiments, Mauthner cell perikarya were injected with radiolabeled full-length BC1 RNA in vivo, fishes were killed after various periods of time, and the Mauthner cell axoplasm and perikarya were isolated and prepared as described in Materials and Methods. Distribution patterns of autoradiographic silver grains were then determined along the axonal extent.

The distribution profile $1 \mathrm{hr}$ after injection showed an advancing wave front at $\sim 8 \mathrm{~mm}$ distal from the soma (Fig. $3 A$ ). The signal distribution produced by injection of the $\mathrm{BC} 15^{\prime}$ segment was very similar to that obtained after injection of full-length $\mathrm{BC} 1$ RNA. The labeling profiles suggest that injected BC1 RNA, and the $\mathrm{BC} 15^{\prime}$ segment, leave the soma and are translocated along the axon in the form of a wave with a diminishing disto-proximal gradient trailing the peak. It was in such regions proximal to the peak that labeling could be observed in the form of spatially restricted focal domains, after low-level injections as described above (Figs. 1, 2). The data thus indicate that these domains are in a region of the axon from which the mobile radioactive front had been cleared, thereby revealing the focal accumulations of the RNA in cortical periaxoplasmic domains.

The axonal BC1 labeling pattern was typical, as is apparent from a compilation of axonal labeling profiles taken at various time points (Fig. 3B,C). The wave front, in particular the trailing slope, becomes broader as it advances along the axon and its height decreases. From the data shown in Figure 3, we calculated the average velocity of the wave front advancing along the axon as 2 $\mu \mathrm{m} / \mathrm{sec}$ (Fig. $3 C$ ). This rate was found to be identical for full-length BC1 RNA and for the BC1 5' segment. Transport of BC1 RNA along Mauthner cell axons can therefore be classified as rapid, with rates comparable to those of fast axonal transport in mammals.

\section{Axonal transport and localization of BC1 RNA: roles of cytoskeletal systems}

A simple interpretation of the above data would suggest that $\mathrm{BC} 1$ RNA is rapidly transported along Mauthner axons and concurrently localized (i.e., "docked") in distinct cortical domains along the axonal extent. The high velocity of anterograde BC1 translocation suggests a role for fast, microtubule-based molecular motors in axonal BC1 transport. To test this hypothesis, we investigated which cytoskeletal components were requisite for such transport. We addressed this question by direct focal microinjection of selective cytoskeletal disrupting drugs into Mauthner axons.

We first examined whether axonal $\mathrm{BC} 1$ transport depended on intact microtubules. Vinblastine, a microtubule-disrupting agent 
A

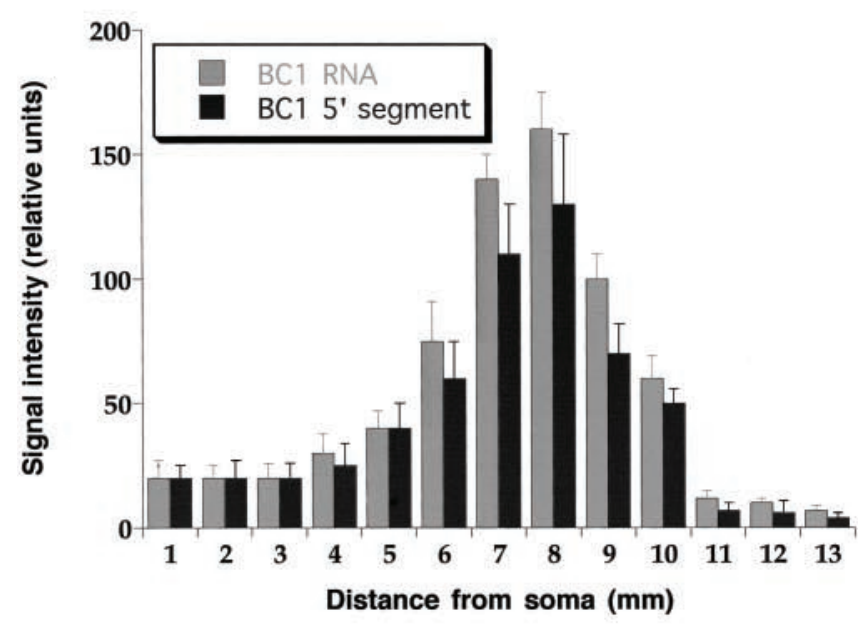

B
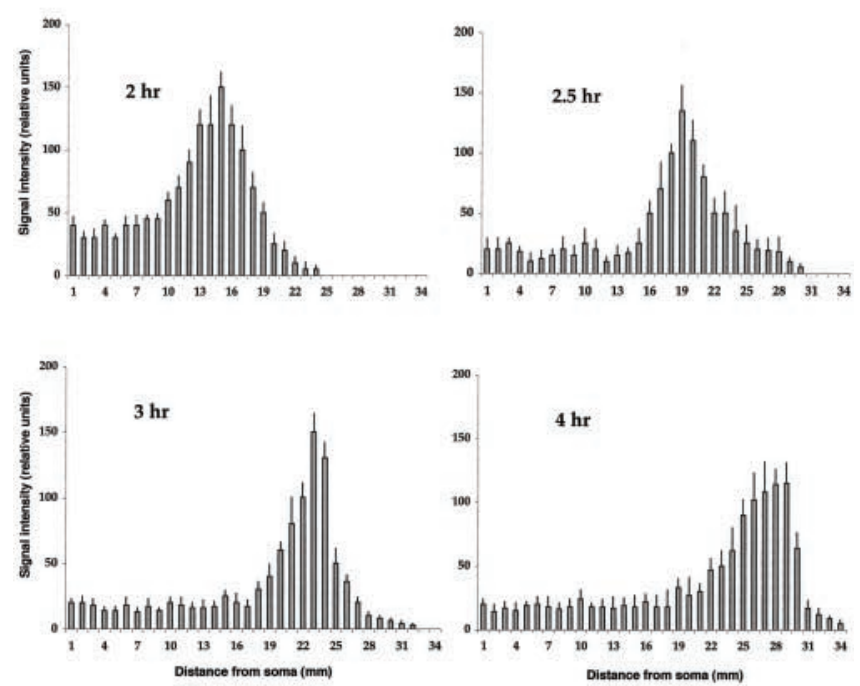

C

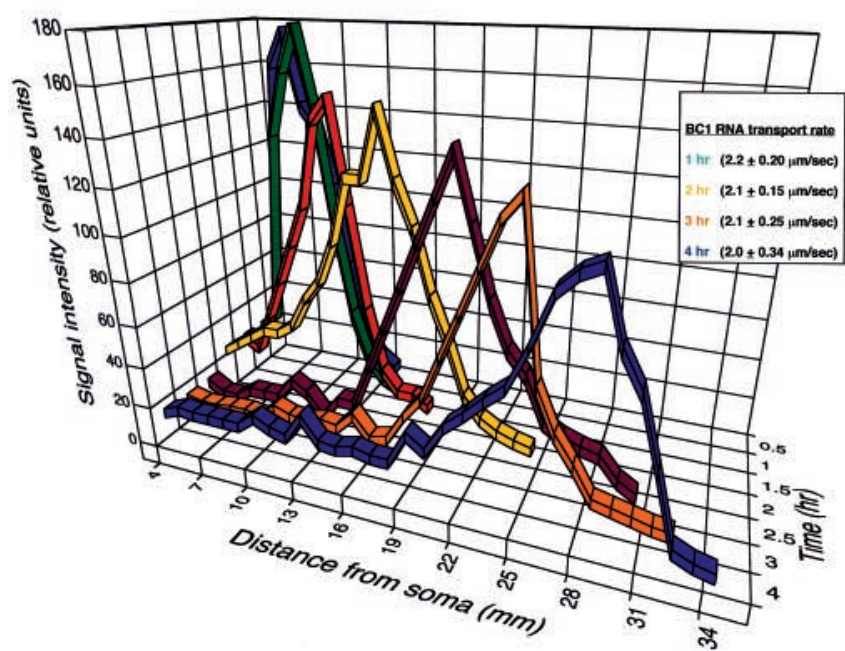

Figure 3. Time-dependent proximo-distal translocation of BC1 RNA along Mauthner cell axons. $A$, Labeling profiles as determined $1 \mathrm{hr}$ after injection into Mauthner somata. Light gray bars indicate full-length BC1 RNA; 24 axons were analyzed. Dark gray bars indicate BC1 5' segment; 15 axons were analyzed. An additional evaluation point (data not shown) was that is specific and effective in the submicromolar range, was microinjected intra-axonally at a distance of $4 \mathrm{~mm}$ from the soma. BC1 RNA was microinjected into the soma of the same cell before intra-axonal vinblastine injection (time differential $20 \pm 5$ min). Axons as well as somata with dendrites were isolated and fixed $1 \mathrm{hr}$ after $\mathrm{BC} 1$ injections. In these experiments (Fig. $4 A-C$ ), BC1 RNA was detected at substantial levels in the area of the axon that was proximal to the vinblastine injection site (Fig. 4B). In sharp contrast, only negligible labeling was observed at a point $8 \mathrm{~mm}$ distal from the soma (Fig. $4 C$ ), an area where the advancing peak of radioactivity was ordinarily detected under standard non-vinblastine conditions after $1 \mathrm{hr}$. Quantitative analysis revealed that $\mathrm{BC} 1$ signal intensities were significant along the axonal extent up to $\sim 3-4 \mathrm{~mm}$ distal from the cell body, at which point the signal decreased precipitously (Fig. $5 A, B$ ). This result contrasted with the situation in control injections (Fig. $3 A$ ) in which the peak of the wave front had progressed to $\sim 8 \mathrm{~mm}$ after $1 \mathrm{hr}$. The data thus indicate that intra-axonal microinjection of vinblastine effectively creates a barrier through which somainjected BC1 RNA cannot traverse.

As a control, and to probe for any involvement of actin filaments in axonal BC1 transport or localization, parallel experiments were performed with cytochalasin D. Cytochalasin D has been used extensively to disrupt actin filaments in living cells, a process that involves an energy-dependent and myosin-driven collapse of the actin network into focal aggregates (Schliwa, 1982; Edmonds and Koenig, 1990). When cytochalasin D was injected intra-axonally instead of vinblastine, somatically injected BC1 RNA was detected in the axon with the highest signal intensity after $1 \mathrm{hr}$ at $\sim 8 \mathrm{~mm}$, i.e., $4 \mathrm{~mm}$ distal to the cytochalasin $\mathrm{D}$ injection site (Figs. $4 D-F, 5 C$ ). Because this is the area of the axon where the advancing wave is typically detected in standard experiments, the results indicate that disruption of axonal actin filaments did not significantly affect axial BC1 transport. This notion was confirmed by quantitative analysis (Fig. $5 C$ ), which showed that axonal labeling profiles in cytochalasin $\mathrm{D}$ experiments were indistinguishable from standard experiments.

Notwithstanding such similarity of axonal labeling profiles, comparison of intra-axonal signal distribution revealed clear differences between cytochalasin D experiments (Fig. $4 D-F$ ) and standard experiments (Fig. 1). In standard experiments, BC1 labeling signal was observed in discrete cortical domains of the axon in areas posterior to the advancing wave front. In contrast, no such cortical concentrations of $\mathrm{BC} 1$ labeling were observed in cytochalasin D experiments. Indeed, the axonal extent posterior to the advancing wave was devoid of any significant BC1 labeling in the

$\leftarrow$

at $0.5 \mathrm{~mm}$, with signal intensities not significantly different from the subsequent three evaluation points. Signal intensities (relative units) were determined at each evaluation point as described in Materials and Methods. From the combined data for full-length BC1 RNA, we calculated the average position of the labeling peak maximum after $1 \mathrm{hr}$ as $7900 \pm 789$ $\mu \mathrm{m}$ (mean $\pm \mathrm{SEM}$ ). The corresponding average transport velocity was $2.2 \pm 0.2 \mu \mathrm{m} / \mathrm{sec}$. For the BC1 5' segment, the respective numbers were $7817 \pm 689 \mu \mathrm{m}$, again yielding an average transport velocity of $2.2 \pm 0.2$ $\mu \mathrm{m} / \mathrm{sec}$. $B$, Profiles of axonal labeling signals at four additional time points after somatic injection of full-length BC1 RNA. Signal intensities were defined and calculated as in $A$. $C$, Synoptic compilation of axonal labeling profiles generated by somatic injection of full-length BC1 RNA. The number of axons analyzed per time point are as follows: $0.5 \mathrm{hr}, 2 ; 1 \mathrm{hr}, 24$; $1.5 \mathrm{hr}, 10 ; 2 \mathrm{hr}, 28 ; 2.5 \mathrm{hr}, 18 ; 3 \mathrm{hr}, 16 ; 4 \mathrm{hr}$, 6 . Error bars have been omitted for clarity. Transport rates were calculated for four time points and are given in the format mean $\pm \mathrm{SEM}$ in the inset. 

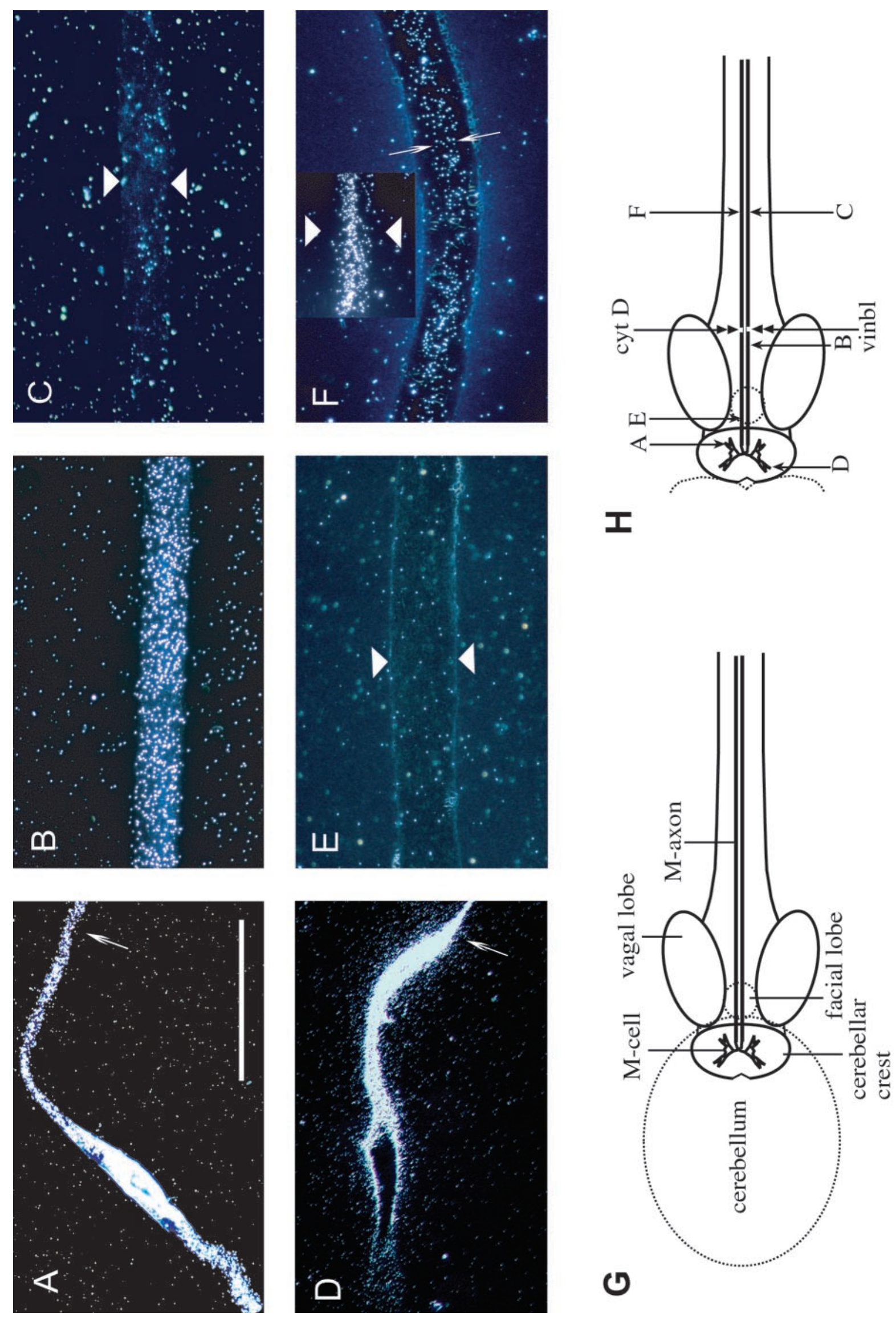
A
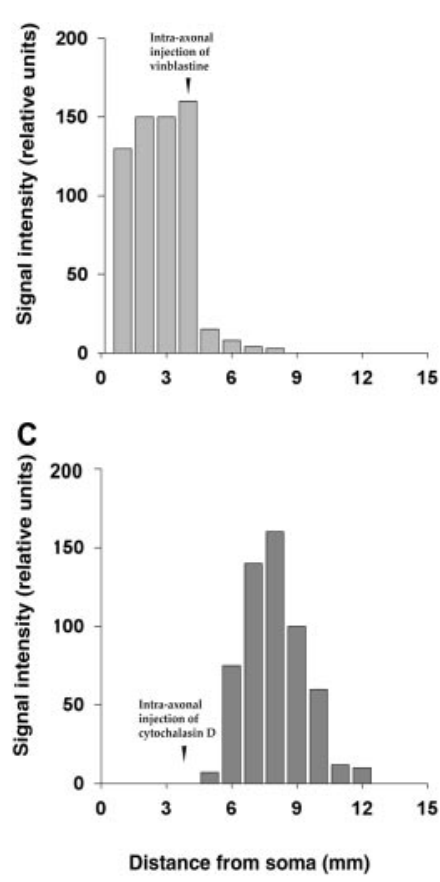

Figure 5. Inhibition by vinblastine of anterograde $\mathrm{BC} 1$ translocation in Mauthner axons. Cells were fixed $1 \mathrm{hr}$ after injection of BC1 RNA. $A, B$, Intrasomatic injection of BC1 RNA was followed after $20 \mathrm{~min}( \pm 5 \mathrm{~min})$ by intra-axonal injection of vinblastine at a distance of $4 \mathrm{~mm}$ from the soma (arrowheads). Two examples (of 7 experiments) are shown. Results were not averaged in these experiments because time intervals between intrasomatic and intra-axonal injections could not be controlled precisely and were therefore variable. $C$, Intrasomatic injection of BC1 RNA was followed after $20 \mathrm{~min}$ ( $\pm 5 \mathrm{~min}$ ) by intra-axonal injection of cytochalasin $\mathrm{D}$ at a distance of $4 \mathrm{~mm}$ from the soma (arrowheads). In three of seven cases, a low but significant signal was observed in the extreme proximal axonal area, directly adjacent to the soma. $D$, Intra-axonal injection of BC1 RNA ( $4 \mathrm{~mm}$ distal from cell body; arrowhead) produced a wave-like labeling pattern with a peak at $11 \mathrm{~mm}$, indicating an anterograde translocation of the RNA at a velocity comparable to the rates observed in Figure 3.

latter case (Figs. $4 E, 5 C$ ). These results indicate that $\mathrm{BC} 1 \mathrm{RNA}$ fails to localize to cortical domains in the presence of cytochalasin D. In further support for this view, we observed that in the peak area representing the advancing wave, BC1 labeling signal remained concentrated in the central domain of the whole mount and was mostly excluded from the cortical regions (Fig. 4F). At times, such central axoplasmic BC1 labeling had a distinctive trail-like appearance (Fig. $4 F$, inset). It thus appears that in the presence of cytochalasin D, BC1 RNA is rapidly transported along the axonal extent but fails to reach cortical axonal domains.
In additional control experiments, $\mathrm{BC} 1 \mathrm{RNA}$ was microinjected intra-axonally at a distance of $4 \mathrm{~mm}$ from the cell body. Again, this produced an anterogradely directed wave front, which now peaked at a distance of $\sim 11 \mathrm{~mm}$ after $1 \mathrm{hr}$ (Fig. $5 D$ ). These experiments demonstrate that intra-axonal microinjection, as such, does not compromise the transport capacity of the axon. Remarkably, both full-length $\mathrm{BC} 1 \mathrm{RNA}$ and the $\mathrm{BC} 15^{\prime}$ domain, injected intraaxonally, were transported anterogradely at the same rate; in contrast, the $\mathrm{BC} 13^{\prime}$ domain was not transported after intra-axonal injection (data not shown). The results also suggest that transacting factors of the microtubule-based molecular transport machinery are ubiquitously available in the Mauthner axon for functional interactions with BC1 RNA.

On the basis of the foregoing experiments, we conclude that fast axonal transport of BC1 RNA in Mauthner neurons is dependent on the integrity of microtubules. Actin filaments, in contrast, although not required for proximo-distal axonal transport of $\mathrm{BC} 1$ RNA, appear to be necessary for radial transport of the RNA and for its localization to cortical periaxoplasmic domains.

\section{DISCUSSION}

Although RNA transport in dendrites has been the subject of a number of studies in recent years, RNA transport in axons has received little attention and remains poorly understood. The fact that axonal RNA transport has so far not been examined directly reflects to a large extent the problem of studying an inaccessible, small-diameter neuronal compartment that is obscured by its ensheathment. This problem has been overcome in selected model systems, such as the squid giant axon and the goldfish Mauthner cell axon, in which it is possible to isolate axoplasm. For the purpose of this work, we elected to use the Mauthner cell, which has been used as a favorable vertebrate neuronal model system for a wide range of studies over the years. Although proximal regions of many invertebrate axons serve dendrite-like functions in providing postsynaptic junctional domains to afferents (for review, see Mohr, 1999), this is clearly not the case for the Mauthner cell axon (Zottoli, 1978). This fact and the ability to identify, independently access, and isolate the three cytoplasmic compartments of this neuron for purposes of analysis make it an ideal system for the questions addressed in this article.

The data presented here show that neuronal BC1 RNA introduced into goldfish Mauthner neurons is rapidly and specifically transported to both axons and dendrites. BC1 transport in Mauthner axons is characterized by a rapidly advancing wave front, reminiscent of similarly advancing waves of radiolabeled proteins in earlier reports of fast axonal transport in mammalian nerve fibers (Ochs, 1972). At $2 \mu \mathrm{m} / \mathrm{sec}$, the BC1 transport rate in Mauthner axons was approximately one order of magnitude

\section{$\leftarrow$}

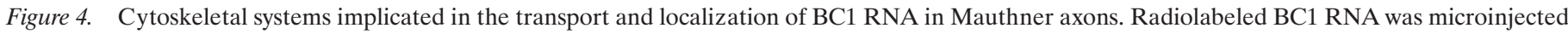

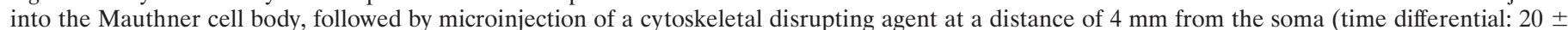

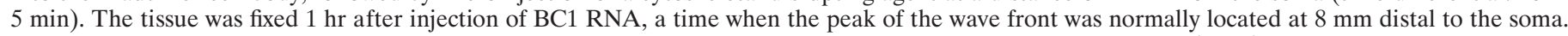

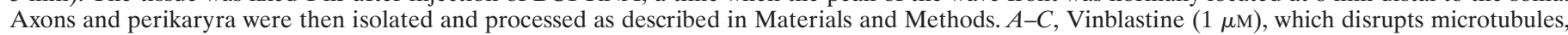

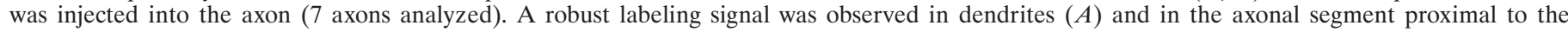

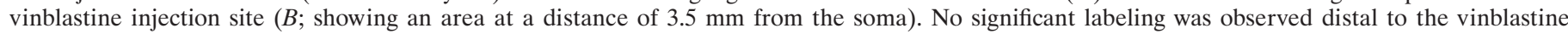

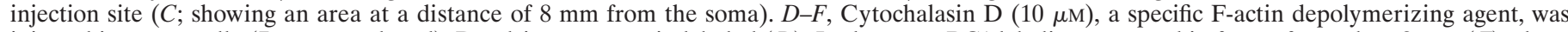

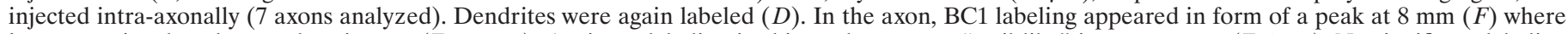

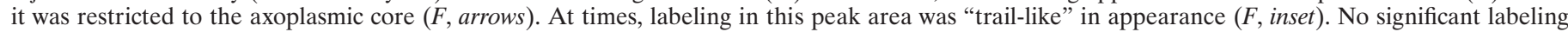

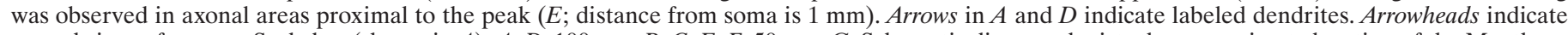

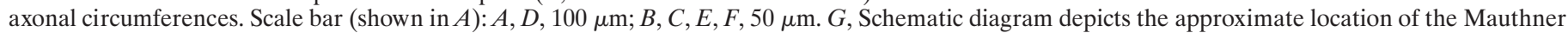

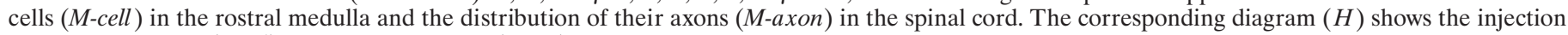
sites of vinblastine (vinbl) and cytochalasin D ( cyt D), as well as the relative locations of regions illustrated in photomicrographs $A-F$. 
higher than the $\mathrm{BC} 1$ transport rate in dendrites, as established previously for sympathetic neurons in culture (Muslimov et al., 1997). Dendritic and axonal transport of BC1 RNA was specific because microinjected RNAs of irrelevant sequence contents remained distinctively restricted to Mauthner cell somata. In addition, injection routines using different RNA concentrations showed that the rate and spatial specificity of BC1 transport were independent of the amounts injected. These controls were important in ascertaining that subcellular RNA distribution reflected genuine RNA transport and localization rather than some unspecific overloading of the cellular RNA transport machinery in Mauthner neurons [see also Muslimov et al. (1997)].

The high velocity of axonal BC1 transport in Mauthner neurons led us to conjecture that fast molecular motors mediate translocation of the RNA along microtubules. This hypothesis was tested in experiments using cytoskeletal disrupting agents. Microtubules were locally disrupted in the axon by microinjections of submicromolar concentrations of vinblastine to test whether the $\mathrm{BC} 1$ wave front would be arrested in its advance along the axon. Indeed, as BC1 was transported into the axon, it accumulated proximal to the vinblastine injection region. The action of vinblastine thus produced a blockade of axonal BC1 transport, a result consistent with the assumption that long-range transport of BC1 RNA in Mauthner axons is dependent on intact microtubules. Intra-axonal microinjection of cytochalasin D, in contrast, did not block BC1 transport; however, localization of the RNA to discrete cortical periaxoplasmic domains was eliminated.

On the basis of these results, we suggest that the targeted delivery of BC1 RNA to local axonal sites is a two-step process. In the first step, long-range fast axial transport of the RNA is mediated by microtubules. Given that axonal microtubules are uniformly oriented with their plus ends distal to the soma (Heidemann et al., 1981; Baas and Ahmad, 1993), we hypothesize that BC1 RNA is transported along axons by a plus-end directed molecular motor (e.g., a kinesin). This hypothesis is further supported by the observation that BC1 RNA, after intra-axonal injection, is transported only in the anterograde direction. In a second step, the RNA is translocated radially and localized to cortical axonal target sites by an actin-based mechanism. The nature of the molecular motor(s) involved in this step remains unknown at this time, but it should be noted that Myo4p, a type V unconventional myosin, has been implicated in actin-mediated RNA transport in yeast (for review, see Chartrand et al., 2001). Two-step RNA delivery pathways have not been reported previously in neurons, although there is precedent for similar mechanisms in Xenopus oocytes (Yisraeli et al., 1990; Rand and Yisraeli, 2001). Functional cooperation between microtubules and actin filaments also appears to be important in granule, vesicle, and organelle transport (for review, see Brown, 1999; Goode et al., 2000).

A BC1 5' domain of no more than 65 nucleotides, previously shown to be responsible for dendritic BC1 transport in mammalian neurons (Muslimov et al., 1997), appears sufficient to specify transport of BC1 RNA to Mauthner cell dendrites and axons, as well as its localization to periaxoplasmic domains at the cortical surface. The BC1 5' domain forms a stem-loop structure of high stability (Deininger et al., 1996; Rozhdestvensky et al., 2001), and it is therefore likely that secondary or higher order structural features of the cis-acting element represent recognition motifs for those trans-acting factors that mediated $\mathrm{BC} 1$ transport and localization. The presence in fish of a $\mathrm{BC} 1$ ortholog has not been demonstrated (e.g., by low-stringency hybridization), and it is therefore possible that the fish counterpart is in fact an analog of rodent $\mathrm{BC} 1 \mathrm{RNA}$, analogous to the rodent-primate $\mathrm{BC} 1-\mathrm{BC} 200$ relationship (Tiedge et al., 1993a). Regardless of the nature of the $\mathrm{BC} 1$ counterpart in fish, however, it is concluded that the $\mathrm{BC} 1$ cis-acting element is recognized by the dendritic and axonal transport machinery in neurons of a non-mammalian vertebrate species. These results suggest an early molecular evolution of at least some key components of neuronal RNA delivery systems.

The results also support the conjecture that the cis-acting targeting element that is contained within the $\mathrm{BC} 15^{\prime}$ domain is recognized by molecular RNA delivery systems in both axons and dendrites. BC1 RNA has been shown previously to be transported along axons of hypothalamic neurons to the posterior lobe of the pituitary (Tiedge et al., 1993b). Localization of BC1 RNA in hypothalamo-neurohypophyseal axons is coordinately regulated with vasopressin mRNA during dehydration and rehydration (Trembleau et al., 1995). It remains to be seen whether BC1 RNA is present in mature mammalian axons other than those of hypothalamo-neurohypophyseal neurons. Thus far, no further evidence has become available to indicate axonal localization or transport of BC1 RNA either in rat brain sections (Lin et al., 2001) or in neurons in primary culture (Muslimov et al., 1997, 1998). It is conceivable, therefore, that axonal localization of BC1 RNA (and other RNAs) in mature mammalian neurons is specific to certain cell types, possibly necessitated by particular protein-synthetic requirements. Alternatively, inasmuch as ribosomal domains are present in mature myelinated mammalian axons (Koenig et al., 2000), BC1 RNA may also be present, but at levels that cannot be detected with the techniques used, particularly if BC1 RNA is restricted to small intermittent periaxoplasmic domains as present observations suggest in the Mauthner axon.

BC1 RNA is transported along Mauthner axons to be localized to discrete, spatially restricted domains at the axonal surface. Dimensions, contours, and in particular the typical location of such BC1 target domains at the axoplasmic surface are of striking resemblance to ribosomal periaxoplasmic plaque domains (Koenig and Martin, 1996). The latter have been identified previously as spatially delimited RNA- and ribosome-containing focal areas that are located at intermittent random intervals along the surface of the Mauthner cell axon (Koenig and Martin, 1996). Such ribosomal plaque domains appeared embedded in the cortical and subcortical actin filament network (Koenig and Martin, 1996), an observation that may be relevant for local RNA delivery and/or anchoring. More recently, $\beta$-actin mRNA has been shown to be concentrated in these domains (Silveira-Sotelo and Koenig, 2000). We hypothesize that BC1 RNA is targeted and localized to such domains of protein synthetic capacity.

A role in translational regulation is also entertained in mammalian dendrites (Brosius and Tiedge, 2001), where BC1 RNA is specifically concentrated in postsynaptic microdomains such as dendritic spines (Chicurel et al., 1993; Rao and Steward, 1993). Although BC1 RNA is not translated itself, its colocalization in such microdomains with dendritic mRNAs and components of the translational apparatus further implies a functional role in local translation regulation (Brosius and Tiedge, 2001). The molecular transport machinery that is responsible for the delivery of BC1 RNA to dendritic spines in mammalian neurons has not yet been analyzed in detail, but it is tempting to speculate, by analogy with the Mauthner axon RNA transport system, about a two-step mechanism encompassing fast, long-range axial transport along dendritic shafts, followed by local, radial translocation to postsynaptic target sites. In summary, therefore, the combined evidence prompts the hypothesis, to be tested in future experiments, that 
noncoding BC1 RNA is specifically delivered, in a two-step mechanism that sequentially involves microtubules and actin filaments, to extrasomatic target sites where it interacts with the translational machinery in the regulation of local protein synthesis.

We conclude by paying homage to A. Goldscheider, who more than 100 years ago first proposed that there is "an actual transport of a material" from the cell body "along the whole course of the axone to its extremity" [as quoted by Barker (1899), p. 307].

\section{REFERENCES}

Alvarez J, Giuditta A, Koenig E (2000) Protein synthesis in axons and terminals: significance for maintenance, plasticity and regulation of phenotype. With a critique of slow transport theory. Prog Neurobiol 62:1-62.

Baas PW, Ahmad FJ (1993) The transport properties of axonal microtubules establish their polarity orientation. J Cell Biol 120:1427-1437.

Banker K, Goslin K (1998) Culturing nerve Cells. Cambridge, MA: MIT.

Barker LF (1899) The nervous system and its constituent neurons. New York: D. Appleton and Company.

Bassell GJ, Zhang H, Byrd AL, Femino AM, Singer RH, Taneja KL, Lifshitz LM, Herman IM, Kosik KS (1998) Sorting of $\beta$-actin mRNA and protein to neurites and growth cones in culture. J Neurosci 18:251-265.

Bleher R, Martin R (2001) Ribosomes in the squid giant axon. Neuroscience 107:527-534.

Brosius J (1989) Superpolylinkers in cloning and expression vectors. DNA 8:759-777.

Brosius J, Tiedge H (2001) Dendritic BC1 RNA: intracellular transport and activity-dependent expression. In: Cell polarity and subcellular RNA localization (Richter D, ed), pp 129-138. Berlin: Springer.

Brown SS (1999) Cooperation between microtubule- and actin-based motor proteins. Annu Rev Cell Dev Biol 15:63-80.

Campbell DS, Holt CE (2001) Chemotropic responses of retinal growth cones mediated by rapid local protein synthesis and degradation. Neuron 32:1013-1026.

Chartrand P, Singer RH, Long RM (2001) RNP localization and transport in yeast. Annu Rev Cell Dev Biol 17:297-310.

Chicurel ME, Terrian DM, Potter H (1993) mRNA at the synapse: analysis of a preparation enriched in hippocampal dendritic spines. J Neurosci 13:4054-4063.

Crispino M, Kaplan BB, Martin R, Alvarez J, Chun JT, Benech JC, Giuditta A (1997) Active polysomes are present in the large presynaptic endings of the synaptosomal fraction from squid brain. J Neurosci 17:7694-7702.

Deininger PL, Tiedge H, Kim J, Brosius J (1996) Evolution, expression, and possible function of a master gene for amplification of an interspersed repeated DNA family in rodents. In: Progress in nucleic acid research and molecular biology, Vol 52 (Cohn W, Moldave K, eds), pp 67-88. San Diego: Academic.

Eberwine J (2001) Molecular biology of axons. "A turning point.” Neuron 32:959-960.

Edmonds BT, Koenig E (1990) ATP and calmodulin dependent actomyosin aggregates induced by cytochalasin $\mathrm{D}$ in goldfish retinal ganglion cell axons in vitro. J Neurobiol 21:555-566.

Eng H, Lund K, Campenot RB (1999) Synthesis of $\beta$-tubulin, actin, and other proteins in axons of sympathetic neurons in compartmented cultures. J Neurosci 19:1-9.

Funch PG, Kinsman SL, Faber DS, Koenig E, Zottoli SJ (1981) Mauthner axon diameter and impulse conduction velocity decrease with growth of goldfish. Neurosci Lett 27:159-164.

Goode BL, Drubin DG, Barnes G (2000) Functional cooperation between the microtubule and actin cytoskeletons. Curr Opin Cell Biol 12:63-71.

Hausner TP, Giglio LM, Weiner AM (1990) Evidence for base-pairing between mammalian U2 and U6 small nuclear ribonucleoprotein particles. Genes Dev 4:2146-2156.

Heidemann SR, Landers JM, Hamborg MA (1981) Polarity orientation of axonal microtubules. J Cell Biol 91:661-665.

Himes RH (1991) Interactions of the catharanthus (Vinca) alkaloids with tubulin and microtubules. Pharmacol Ther 51:257-267.

Job C, Eberwine J (2001) Localization and translation of mRNA in dendrites and axons. Nat Rev Neurosci 2:889-898.

Kindler S, Mohr E, Richter D (1997) Quo vadis: extrasomatic targeting of neuronal mRNAs in mammals. Mol Cell Endocrinol 128:7-10.

Koenig E (1986) Isolation of native Mauthner cell axoplasm and an analysis of organelle movement in non-aqueous and aqueous media. Brain Res 398:288-297.

Koenig E (1991) Evaluation of local synthesis of axonal proteins in the goldfish Mauthner cell axon and axons of dorsal and ventral roots of the rat in vitro. Mol Cell Neurosci 2:384-394.

Koenig E, Adams P (1982) Local protein synthesizing activity in axonal fields regenerating in vitro. J Neurochem 39:386-400.

Koenig E, Giuditta A (1999) Protein-synthesizing machinery in the axon compartment. Neuroscience 89:5-15.

Koenig E, Martin R (1996) Cortical plaque-like structures identify ribosome-containing domains in the Mauthner cell axon. J Neurosci 15:1400-1411.

Koenig E, Repasky EA (1985) A regional analysis of $\alpha$-spectrin in the isolated Mauthner neuron and in isolated axons of the goldfish and rabbit. J Neurosci 5:705-714.

Koenig E, Martin R, Titmus M, Sotelo-Silveira JR (2000) Cryptic peripheral ribosomal domains distributed intermittently along mammalian myelinated axons. J Neurosci 20:8390-8400.

Lin Y, Brosius J, Tiedge H (2001) Neuronal BC1 RNA: co-expression with growth-associated protein-43 messenger RNA. Neuroscience 103:465-479.

MacLean-Fletcher S, Pollard TD (1980) Mechanism of action of cytochalasin B on actin. Cell 20:329-341.

Martin R, Vaida B, Bleher R, Crispino M, Giuditta A (1998) Protein synthesizing units in presynaptic and postsynaptic domains of squid neurons. J Cell Sci 111:3157-3166.

Mohr E (1999) Subcellular RNA compartmentalization. Prog Neurobiol 57:507-525.

Muslimov IA, Santi E, Homel P, Perini S, Higgins D, Tiedge H (1997) RNA transport in dendrites: a cis-acting targeting element is contained within neuronal BC1 RNA. J Neurosci 17:4722-4733.

Muslimov IA, Banker G, Brosius J, Tiedge H (1998) Activity-dependent regulation of dendritic BC1 RNA in hippocampal neurons in culture. J Cell Biol 141:1601-1611.

Ochs S (1972) Rate of fast axoplasmic transport in mammalian nerve fibres. J Physiol (Lond) 227:627-645.

Rand K, Yisraeli J (2001) RNA localization in Xenopus oocytes. In: Cell polarity and subcellular RNA localization (Richter D, ed), pp 157-173. Berlin: Springer.

Rao A, Steward O (1993) Evaluation of RNAs present in synaptodendrosomes: dendritic, glial, and neuronal cell body contribution. J Neurochem 61:835-844.

Rozhdestvensky T, Kopylov A, Brosius J, Hüttenhofer A (2001) Neuronal BC1 RNA structure: evolutionary conversion of a tRNA ${ }^{\text {Ala }}$ domain into an extended stem-loop structure. RNA 7:1-9.

Schliwa M (1982) Action of cytochalasin D on cytoskeletal networks. J Cell Biol 92:79-91.

Silveira-Sotelo JR, Koenig E (2000) Localization of $\beta$-actin mRNA in cryptic ribosomal periaxoplasmic plaque domains of myelinated axons. Mol Biol Cell [Suppl] 11:154a.

Tiedge H (1991) The use of UV light as a cross-linking agent for cells and tissue sections in in situ hybridization. DNA Cell Biol 10:143-147.

Tiedge H, Fremeau Jr RT, Weinstock PH, Arancio O, Brosius J (1991) Dendritic location of neural BC1 RNA. Proc Natl Acad Sci USA 88:2093-2097.

Tiedge H, Chen W, Brosius J (1993a) Primary structure, neural-specific expression, and dendritic location of human BC200 RNA. J Neurosci 13:2382-2390.

Tiedge H, Zhou A, Thorn NA, Brosius J (1993b) Transport of BC1 RNA in hypothalamo-neurohypophyseal axons. J Neurosci 13:4114-4219.

Tiedge H, Bloom FE, Richter D (1999) RNA, wither goest thou? Science 283:186-187.

Trembleau A, Melia KR, Bloom FE (1995) BC1 RNA and vasopressin mRNA in rat neurohypophysis: axonal compartmentalization and differential regulation during dehydration and rehydration. Eur J Neurosci 7:2249-2260.

van Minnen J (1994) RNA in the axonal domain: a new dimension in neuronal functioning? Histochem J 26:377-391.

Wilson L, Bamburg JR, Mizel SB, Grisham LM, Creswell KM (1974) Interaction of drugs with microtubule proteins. Fed Proc 33:158-166.

Yisraeli JK, Sokol S, Melton DA (1990) A two-step model for the localization of maternal mRNA in Xenopus oocytes: involvement of microtubules and microfilaments in the translocation and anchoring of Vg1 mRNA. Development 108:289-298.

Zhang HL, Eom T, Oleynikov Y, Shenoy SM, Liebelt DA, Dictenberg JB, Singer RH, Bassell GJ (2001) Neurotrophin-induced transport of a $\beta$-actin mRNP complex increases $\beta$-actin levels and stimulates growth cone motility. Neuron 31:261-275.

Zheng JQ, Kelly TK, Chang B, Ryazantsev S, Rajasekaran AK, Martin KC, Twiss JL (2001) A functional role for intra-axonal protein synthesis during axonal regeneration from adult sensory neurons. J Neurosci 21:9291-9303.

Zottoli SJ (1978) Comparative morphology of the Mauthner cell in fish and amphibians. In: Neurobiology of the Mauthner cell (Faber DS, Korn H, eds), pp 13-45. New York: Raven. 